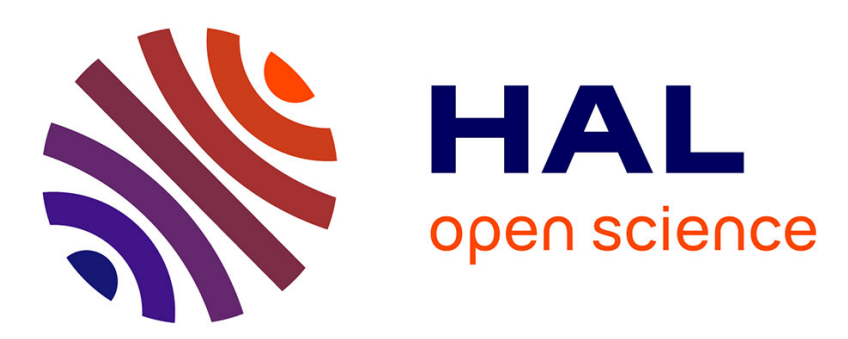

\title{
Balancing costs and benefits in primates: ecological and palaeoanthropological views
}

Cécile Garcia, Sébastien G Bouret, François Druelle, Sandrine Prat

\section{To cite this version:}

Cécile Garcia, Sébastien G Bouret, François Druelle, Sandrine Prat. Balancing costs and benefits in primates: ecological and palaeoanthropological views. Philosophical Transactions of the Royal Society B: Biological Sciences, 2021, 376 (1819), pp.20190667. 10.1098/rstb.2019.0667 . hal-03128979

\section{HAL Id: hal-03128979 \\ https://hal.sorbonne-universite.fr/hal-03128979}

Submitted on 2 Feb 2021

HAL is a multi-disciplinary open access archive for the deposit and dissemination of scientific research documents, whether they are published or not. The documents may come from teaching and research institutions in France or abroad, or from public or private research centers.
L'archive ouverte pluridisciplinaire HAL, est destinée au dépôt et à la diffusion de documents scientifiques de niveau recherche, publiés ou non, émanant des établissements d'enseignement et de recherche français ou étrangers, des laboratoires publics ou privés. 
Balancing costs and benefits in primates: ecological and paleoanthropological views

Garcia Cécile ${ }^{1^{*}}$, Bouret Sébastien ${ }^{2}$, Druelle François ${ }^{3,4}$, Prat Sandrine ${ }^{5}$

${ }^{1}$ UMR 7206, CNRS-Muséum national d'Histoire naturelle-Université de Paris, Musée de I'Homme, 17 Place du Trocadéro, 75016 Paris, France, orcid.org/0000-0002-2591-5245

2 Institut du Cerveau (ICM), CNRS UMR 7225 - INSERM U1127 - UPMC UMR S 1127, Hôpital PitiéSalpêtrière 47, boulevard de l'Hôpital, 75013 Paris, France, orcid.org/0000-0003-2279-6161

${ }^{3}$ UMR 7194 (Histoire Naturelle de l'Homme Préhistorique), CNRS-Muséum national d'Histoire naturelleUPVD, Musée de I'Homme, 17 Place du Trocadéro, 75016 Paris, France, orcid.org/0000-0001-9680-6401

${ }^{4}$ Functional Morphology Laboratory, University of Antwerp, Campus Drie Eiken, Universiteitsplein 1, 2610 Antwerp, Belgium

${ }^{5}$ UMR 7194 (Histoire Naturelle de l'Homme Préhistorique), CNRS-Muséum national d'Histoire naturelleUPVD, Musée de I'Homme, 17 Place du Trocadéro, 75016 Paris, France, orcid.org/0000-0003-3024-1959

* Author for correspondence: cecile.garcia@mnhn.fr 


\section{Summary}

Maintaining the balance between costs and benefits is challenging for species living in complex and dynamic socio-ecological environments, such as primates, but also crucial for shaping life history, reproductive and feeding strategies. Indeed, individuals must decide to invest time and energy to obtain food, services and partners, with little direct feedback on the success of their investments. Whereas decision-making relies heavily upon cognition in humans, the extent to which it also involves cognition in other species, based on their environmental constraints, has remained a challenging question. Building mental representations relating behaviours and their long-term outcome could be critical for other primates, but there is actually very little data relating cognition to real socio-ecological challenges in extant and extinct primates. Here, we review available data illustrating how specific cognitive processes enable(d) modern primates and extinct hominins to manage multiple resources (e.g. food, partners) and to organize their behaviour in space and time, both at the individual and at the group level. We particularly focused on how they overcome fluctuating and competing demands, and select courses of action corresponding to the best possible packages of potential costs and benefits in reproductive and foraging contexts. 


\section{Introduction}

Understanding the balance between costs and benefits is a central research goal of economists, behavioural ecologists and paleoanthropologists. By analogy with economical markets, biological markets refer to the exchange of commodities (e.g. food resources and services such for example grooming) between individuals belonging (or not) to the same species [1]. In that frame, individuals choose among a number of potential partners or between resources of differing values based on their expected net benefits (e.g. feeding or reproductive benefits in terms of energy input or fitness advantage), given their expected costs (e.g. distance travelled and energy expenditure to reach the partner or the resource, and the associated risks and dangers). The exchange of commodities is determined by the law of supply and demand, and depends upon intrinsic (e.g. physiology) and extrinsic (e.g. environmental, social) factors [2-3]. But beyond the analogy with financial markets, one can wonder what are the behavioural strategies and the actual mechanisms involved in decisions in animals.

For all animal species, decision-making implies identifying the best course of action given all the available alternatives, to optimize the costs and the benefits linked to a particular behaviour in a particular context. But the underlying mechanisms regulating decision-making could take a variety of forms, ranging from a set of simple behaviours such as reflexes to critical environmental events (stimuli) to high-level cognitive representations of potential actions and their consequences. All species display reflexes that enable them to avoid predators or potentially costly actions, and to approach potential sources of food or sexual partners [4]. These reflexes are thought to have evolved in order to provide optimal behavioural responses in relatively stable socio-environments, in which they could be sufficient to enable approaching an optimal trade-off between costs and benefits. But, such stereotyped behavioural responses would probably not be sufficient for species living in complex and rapidly changing socio-environments. For such species, actions are most probably also controlled by executive processes, which enable individuals to organize their behaviour in space and time. By contrast with reflexes, these behaviours [5] are modulated by a cognitive representation of the goal, which includes the outcome value.

In humans, it is generally accepted that decision-making involves computing the value of distinct options using cognitive processes, and the resulting choice consists in maximizing the benefits/costs ratio [6-7]. These processes include computing the options' value, episodic representation and memory (i.e. the ability to recall specific events in the past), long-term planning (i.e. the capacity to mentally envisage its own needs in the future, and to act now to maximize the chance that they can be met), executive control (i.e. a flexible and goal-dependent control of behaviour, overriding reflexive responses), and transitive inferences (i.e. a form of deductive reasoning allowing to derive a relation between items that have not been explicitly compared before) [6-10]. But the extent to which other species use such cognitive processes remains unclear (e.g. [11-14]). Moreover, understanding the variability of the cognitive processes that are mobilized across species showing distinct socio-ecological features still remains a challenging issue.

Several elements suggest that primates (both modern and extinct species) are good models for understanding the variability in the cognitive processes associated with decision-making over a long- 
time frame. Indeed, since most primate species live in complex socio-environments, behaviours related to foraging, socializing and reproduction all involve complex decisions contingent on the environmental context [15], where potential costs and benefits include numerous parameters. Moreover, as long-lived animals, primates (especially gregarious species) have to deal with long-lasting social interactions that can incur delayed benefits and requires evaluating other individuals over a long time. Indeed, when competing or cooperating with one other, social animals must make rapid, adaptive decisions based not only on the current behaviour of their social partner or competitor, but also on the history of their past interactions with those individuals and those individuals' allies and kin [16]. Thus, at least at this general level, the socio-ecological system appears complex enough to require cognitive processes, which provide the behavioural flexibility that enables primates to respond optimally to rapidly changing constraints. Thereby, natural selection should be favoring species/individuals that possess the cognitive skills allowing them to flexibly adapt to changing environments and to make rapid decisions about when/whether to forage/mate/socialize and with whom.

Our aim here is to provide concrete elements of behavioural ecology and paleoanthropology supporting the idea that several primate species could use cognitive skills to make complex decisions, needed to overcome specific socio-ecological challenges. In our conceptual frame, the relative development of these cognitive processes across species should be directly related to the nature and the extent of socioecological challenges. Thus, rather than trying to examine directly the expression of cognitive processes across hominins and other primates, we will consider some of the socio-ecological conditions that might require these processes, and will use a comparative approach to discuss the extent to which different primate species (both modern and extinct) could rely upon cognitive processes, rather than reflexes, to make decisions about the ratio between costs (e.g. energy expenditure, dangers, risks) and benefits (in terms of food, services and sexual partners).

We will consider the cost-benefit perspective of a range of behaviors relevant to hominins and other primates living in different socio-ecological contexts that could promote or constrain the occurrence of these economic behaviours. We will tackle this complex regulation of costs and benefits at two levels, at the individual level (i.e. individual decisions based on the sensory environment and individual characteristics) and the collective level (i.e. decisions made by a group of individuals that increases their beneficial outcome relative to acting alone (cooperation) or could result in unbalanced costs/benefits (competition)). For this, we will present the possible cognitive and physiological mechanisms (neural and endocrine) involved in two detailed examples of economic strategies, from actual and extinct populations, used to balance costs and benefits at the individual level in the context of reproduction (e.g. mating decisions) and at the collective level in the context of foraging (e.g. hunting). With this review paper, we aim at illustrating the complexity and diversity that can be found in the primate order when making adaptive decisions related to the optimization of benefits and costs.

\section{BALANCING COSTS AND BENEFITS AT THE INDIVIDUAL LEVEL}

\section{Reproductive strategies and mating decisions}


Differential costs/benefits trade-offs should lead individuals to allocate their time, energy, and effort to activities in ways that increase their fitness, so that they evolved conditional strategies guided by environmental cues. In the case of sexual activities, mating strategies involve multiple behavioural tactics, i.e. specific actions in which individuals will engage when pursuing a given strategy. These strategies will influence how and when individuals select mates, the proportion of time and energy they invest in those activities (vs. others like foraging), and how much mating effort and parental effort they spend. In those particular cases (mating vs. foraging; parenting vs. mating effort), the two "commodities" can be considered as two options, for which both availability and value fluctuate in time. These two options are particularly competing in species where conception peaks occur during periods of high fruit availability (e.g. sifakas (Propithecus spp.), orangutans (Pongo spp.) [17]) or where mating is strictly seasonal (e.g. Japanese macaques (Macaca fuscata) [18]; Assamese macaques (Macaca assamensis) [19]), which means that if an individual fails to mate during one mating season, his reproduction is delayed by an entire year (i.e. a greater impact on fitness than in non-seasonal species). By analogy with food, for which value depends (negatively) upon availability [20], we expect an influence of females 'availability and monopolization on male's mating decisions and an influence of the operational sex ratio (i.e. the ratio of the number of fertile adult males to the number of potentially fertile females in a group at a given time) on the choosiness of females on the mating market. Moreover, rewards are devalued by the costs of waiting or physical energy necessary to obtain them [21], such that the amount of time and/or energy spent for the search of a(nother) partner, together with the increased predation risks during searches and investment in the assessment of the potential partners, imply a significant amount of effort that individuals must make in order to mate.

This has two critical implications: individuals should choose mates not only based on their potential benefits, such as high reproductive quality and dominance status, but also based on potential costs (delay, effort, etc.). Individuals should thus be able to dynamically and flexibly integrate information about these potential benefits and costs and generate an appropriate decision rule. Given the complexity of social interactions in primates, a significant part of this information implies high-level cognitive representations because it is not directly explicit [6-7, 22]. For example, choices should be based on the recognition of other individuals' relative dominance ranks and social relationships, but also on the nature and quality of recent interactions, the value of particular partners and perhaps even other individuals' intentions [23]. Thus, it seems that mating decisions are unlikely limited to reflexes to simple stimuli and presumably involve cognitive processes. In laboratory settings, the exertion of cognitive control (to overcome reflexes and obtain a more costly but more favourable reward) implies a specific set of prefrontal cortical structures including the dorso-lateral prefrontal cortex and the anterior cingulate cortex [8-10]. Thus, it is likely that the relative development of these brain structures across species scales with the amount of cognitive control associated with mating. Testing this hypothesis would require comparing the relative size of these brain regions across species characterized by distinct levels of mating-associated costs. For example, these structures should be more developed in species for which breeding is seasonal, since seasonality implies more temporal constraints on the general organization of behaviour. Along the same lines, these structures should be more developed in species displaying costly behaviours, i.e. paying short-term costs to allow a long-term benefit for reproduction (e.g. mate guarding, see below). Indeed, paying immediate costs for later benefits (delay discounting, 
typically) is known to require cognitive control and prefrontal cortex activation in laboratory settings [810]. But beyond these general principles that apply to both sexes, each sex must make rapid and adaptive mating decisions depending on the specific constraints that it faces.

\section{THE PERSPECTIVE OF MALES}

Primate males constantly need to make mating decisions which imply mitigating the costs associated with mating activities (e.g. physiological and physical costs: intra-sexual competition and associated aggressions, increased vigilance, altered travel and grouping patterns, chronic stress and reduced feeding time or efficiency, mate guarding [24-27]) and increasing the benefits (i.e. achieving a higher reproductive success). Male mating tactics in general, and mate guarding decisions in particular, vary in both costs and benefits and are influenced by individual features, such as competitive ability or energetic status, and by contextual factors, such as reproductive seasonality, the number and quality of sexually-available females, the number of competitors, and food availability [28]. Thereby, males of seasonal breeding species can most likely afford to engage fully in stressful intra-sexual competition and female guarding over a short period of time without facing the high risk of exposure to chronic stress. In contrast, males of species with unpredictable timing of reproduction are more likely to face long-term exposure to physiological stress and may thus have evolved an "incomplete female monopolization strategy" in order to limit this cost [29]. In cases where ecological pressures are very high (territory defence, predation [19]), i.e. making the male unable to guard females effectively, mate-guarding behaviours can even be totally absent. Moreover, a high female cycle synchrony will limit the possibility of mate guarding and mating all females during a short period of time, just as the male's sensory abilities to discriminate the timing of ovulation within a cycle (e.g. $[18,30])$ or the reproductive potential of a female will affect mate guarding activity and mating success. Food availability is also expected to influence the decisions to engage or not in costly mate guarding behaviours. In a context where males trade-off feeding time against vigilance time (which is energetically demanding and stressful, since mental effort is costly [8-10]) to monitor females, it is also expected that males would make the decision to favour energetic needs over mate guarding investment in period of food shortage (e.g. [31]), in order

to prevent an exposure to chronic energetic stress. Finally, rank is also known to influence mate guarding behaviours, and in a context where the alpha male monopolizes females, a balanced decisionmaking for subordinate males would consist of either using sneaky copulations (which presumably involves metacognitive processes) or giving up copulations during the ovulation window until opportunities of mating increase again (which are probably associated with a decrease in fertilization success).

The underlying physiological mechanisms regulating male socio-sexual behaviours, and particularly mate guarding behaviours, seem to involve temporal fluctuations in androgen levels, with the "challenge hypothesis" being broadly used to conceptualise those relationships [32-33]. For instance, it has been shown that, in a breeding context, androgen levels increased during consortships (e.g. savanna baboons (Papio cynocephalus) [34]; chacma baboons (Papio ursinus) [35]), in the presence of fertile females (white-faced capuchins (Cebus capucinus) [36]; chimpanzees (Pan troglodytes) [37]), and correlated positively with the occurrence of mate guarding behaviour (e.g. savanna baboons [34]; long-tailed 
macaques (Macaca fascicularis) [38]). Moreover, a revision of the "challenge hypothesis" predicts a stronger androgen response to challenges associated with high fitness benefits [39], which is the case for mate guarding that has been shown to significantly increase male reproductive success in a number of primate species, especially for high-ranking individuals (rhesus macaques (Macaca mulatta) [40]; long-tailed macaques [41]; Japanese macaques [42]; mandrills (Mandrillus sphinx) [43]). This is particularly true in species where there is a high level of monopolization of females (e.g. chimpanzees, savanna baboons, mandrills, long-tailed macaques, white-faced capuchins [36, 41, 43]), i.e. species in which being a high-ranking male provides a substantial reproductive advantage and in which, as a consequence, males challenge other males to achieve high ranks. In this case, individual males may further optimize their competitive abilities by raising their androgen levels (which facilitate the expression of aggressive behaviours [44] and enhance muscle performance) above those of their conspecifics only when the reproductive benefits of doing so are high enough and outweigh the potential costs of elevated androgen concentrations (e.g. physiological costs such as the downregulation of immune function, increase in metabolic rates, energetic costs and increased predation risk [33]). Elevated androgen levels during mate guarding might also be beneficial as they enhance males' abilities to monitor females, the efficiency of vigilance [29], and help in sustaining directed attention [44]. Finally, an increase in androgens promotes sperm production [25], which in turn enhances the chance for the mate guarding male to fertilize the guarded female. Collectively, it seems that elevated androgen levels during mate guarding increase the fitness benefits derived from this behaviour, but these benefits will also depend on the quality of mating opportunities available, i.e. on female reproductive and social value (strength of female-male bonding) and on female's mating preferences (see below).

Males are predicted to allocate their mating effort toward the most valuable females, with males preferentially mating with high-ranking and/or parous females (who have a better access to food resources and often produce more offspring and offspring of better quality [45-46]) (e.g. long-tailed macaques [31], chimpanzees [47]; mandrills [48]; savanna baboons [49]; Japanese macaques [18]). In some species, males also exhibit mating preferences towards females with whom they have strong social bonds (see below, "friendships"), independent of female rank, parity or fertility status (e.g. savanna baboons [49]; rhesus macaques [50]; Japanese macaques [51]). Besides biasing their mate choice toward certain females, males of several species also seem to modulate their investment according to the likelihood of ovulation/conception (long-tailed macaques [52]; chacma baboons [53]; Japanese macaques [18]; mandrills [43]; white-faced capuchins [36]). The concentration of mating effort to the time when fertilization is most probable might be a way of conserving energy and limiting energy expenditure, especially in species where there are frequent ejaculations, which are costly to produce [54]. However, the question of whether males do act in a manner indicating that they have the ability to make mating choices based on ovulatory/conceptive probabilities still remains to be investigated. Similarly, whether male primates have the cognitive abilities to track the fertility status of several females simultaneously while mate guarding remains to be explored. This also leads to questions about what explicit cues males might be using to track female reproductive status, and to what extent they rely upon mental representations (rather than explicit cues) to infer the female reproductive value. Moreover, even if physiological changes (e.g. hormonal levels) are likely influencing mating decisions, 
the relative influence of these physiological processes on reflexes vs. cognitive processes also remains an open question.

In conclusion, males continuously adjust their mating decisions to maximize the benefits vs. the costs. The more these decisions rely upon integrating a multitude of socio-ecological factors, the more they should rely upon cognitive functions, which enable flexible planning and overcome reflexes to simple stimuli.

\section{THE PERSPECTIVE OF FEMALES}

As discussed above, evolution should favour male mating decisions such that those decisions bring benefits both at proximate (reduced costs of mating activity) and ultimate (higher reproductive value) levels. This also, and even more, applies to females, because they are usually the sex that bear higher reproductive costs [55], and hence, they should be more selective in their mating decisions. Moreover, because female primates have slow life histories, long investment period and produce relatively few offspring, mate selectivity is expected to be relatively high in this order [56], but with higher sexual dimorphism and higher reproductive skew leading to a decreased role for female mate choice (e.g. greater scope for direct female choice in rhesus macaques vs. mandrills for example). Female mating decisions are indeed constrained by male aggression and sexual coercion ([57]: forced copulation, harassment (repeated attempts to copulate inducing eventual female submission), intimidation (physical punishment of female refusals to mate increasing the likelihood of matings in the future) and mate guarding), especially in male-dominant species such as baboons or chimpanzees. Sexual coercion is often a long-term strategy that achieves its goal by manipulating the future, rather than simply the immediate behaviour of the victim [58]. Such coercion imposes costs on females, in terms of energy spent to escape from males and in terms of increased physiological stress [59]. Trading these costs implies that females will compete for mate quality (and/or number) or for other benefits, such as protection or increased access to resources [60]. Such a scenario may be particularly relevant if sexual (e.g. "good quality" mates) and non-sexual (e.g. food, social benefits) resources are limited.

Females can mate promiscuously, allowing sperm competition and/or cryptic female choice to operate (review in [54]). Alternatively, females may exert choice for mate directly by mating selectively. Females can also follow a mixed strategy of promiscuity and selective mating (i.e. mating with multiple males throughout their mating period but with different mating rates between males during the fertile period). The proportion of promiscuous and selective mating undertaken by a female within a mating period is most likely shaped by trade-offs between costs and benefits (see [61] for discussion). Thereby, if females can discriminate males based on heritable traits conferring benefits to offspring, then females will be expected to mate exclusively with the best males. However, if these advantageous and heritable traits are associated with the males' sperm, it is unlikely that females will identify individual males' quality and, in this context, females are predicted to mate promiscuously so that sperm from various males will compete for fertilization, with possible benefits such as a reduced risk of infertility, increased protection of offspring against predators, increased investment to offspring by multiple males and genetic diversity. 
When females exert direct (i.e. precopulatory) choice, male traits that females might select for in a mate are dominance rank, unfamiliarity (for avoidance of infanticide or inbreeding), and sexual ornaments and weapons (badges of status [25]). Female choice of high-ranking males is predicted, for example, in species when there is a risk of male infanticide (e.g. chimpanzees), with the high-ranking male being able to provide the best defence of the offspring. However, in species vulnerable to infanticide, unbiased promiscuity (and longer receptive period) could also act as a counterstrategy to confuse paternity [62] and protect the offspring.

Besides social rank, females can also base their mating decisions on sexually dimorphic male ornaments, such as the red face and genital sex skin in mandrills and Japanese macaques, the cheek flanges of orangutans (Pongo spp.), enlarged noses of proboscis monkeys (Nasalis larvatus), etc. (see [25]). Some of these testosterone-dependent traits (e.g. nose size in proboscis monkeys [63], face redness in mandrills [64], darkness of chest stain in sifakas [65]) have been suggested to serve as advertisements to females in their mate selection and to influence female preferences, with females preferring for instance redder/darker males (rhesus macaques [66]; mandrills [67]). Using such traits could enable mating decisions to be achieved by reflexes, but since these decisions also involve several social components, cognitive processes are likely at play to enable efficient decisions.

Females might also select a male based on the bonds they have created with him, also called "friendships" (i.e. close spatial proximity, frequent affiliative behaviour and low rates of aggression between males and non-fertile or lactating females $[49,68])$. These strong ties have been reported in a number of cercopithecine primates (e.g. olive baboons (Papio anubis) [69]; Barbary macaques (Macaca sylvanus) [70], Assamese macaques [71]). These male-female bonds may represent a form of male parenting effort enhancing the survival of female's progeny. Indeed, females will get direct benefits such as protection of their offspring against harassment by other females (yellow baboons [72]), offspring care and access to food resources. These female benefits can be of particularly high value in species in which feticide and/or infanticide are important sources of mortality (e.g. chacma baboons [73]; yellow baboons [74]), but also in species in which infanticide is rare, as males may protect both mothers and infants from predation or non-lethal harassment by conspecifics [68, 72]. A recent study in olive baboons also showed that females' ties to the sires of their current infants often persisted after they resumed cycling which suggested that males may continue to provide benefits after infant's weaning [75]. For the male friend, the benefits that can be obtained could consist of a) using their friends' offspring as buffers against attacks from other males, b) receiving grooming which confers both health and social benefits and could be traded (as a commodity in biological markets [76]) in exchange for itself or for other services, c) increasing their attractiveness as mates and gaining additional matings (presently or in the future) with other females who observe his behaviour [77], d) in some cases, having higher chances of copulating with his friend and siring the friend's next offspring when she will resume cycling ("care-then-mate" hypothesis proposing that close ties between males and females represent a form of male mating effort [70, 75]; but see also [71, 72]: ties to lactating females did not predict male consort success or the probability of siring the female's next infant). This last case (d) assumes that females prefer to mate with males that behave benevolently towards them and their current offspring; it also assumes that females can express active mate choice, i.e. that it is limited to species in which the 
extent of male reproductive skew is low (e.g. olive baboons). This means that individuals may choose whom to mate with based on benefits they got in the recent past or expect to get from this behaviour. This also means that males can identify their own offspring with some degree of accuracy (i.e. paternal kin recognition). Thereby, the male's decisions to form a friendship with a particular mother-infant dyad could be based on phenotype-matching or behavioural proxies that are reliably associated with paternity [78], such as the mating history or more generally the strength of the relationship with the female around the time of conception to gauge their probability of paternity ([79]: "males may benefit by investing preferentially in those infants that they are most likely to have fathered"). However, friendships also incur some opportunity costs for males, in that it may reduce the current likelihood of mating with other females. Moreover, favours are not immediately traded but are rather based on longterm equitability that may, in fact, be violated in favour of one partner over short periods, but which is tolerated by the other partner by virtue of the long-term benefits. Therefore, males should make decisions about pursuing or giving up friendships, taking into account the costs associated with those aborted mating opportunities while representing putative long-term benefits associated with potential future copulations with his female friend.

At the physiological level, the underlying mechanisms regulating female socio-sexual behaviours involve glucocorticoid hormones (since having a male friend could buffer lactating females from the stress associated with heightened infanticide) and temporal fluctuations in oestradiol and progesterone levels, with oestradiol enhancing sexual behaviour and progesterone having inhibitory effects [25]. In strepsirhines, there is a behavioral estrus period around ovulation to which mating is restricted, with a strict hormonal control. In haplorhines, sexual receptivity (female's willingness to accept the male's mounts and to facilitate intromission and ejaculation during copulation) is no longer under strict hormonal control and mating may occur throughout the cycle. The extent to which variation in sexual hormone levels will be associated with female proceptivity (i.e. active male solicitations), receptivity and attractivity (i.e. female's value as a sexual stimulus) will vary across species and across social contexts [18]. In nearly all species, sexual behaviours increase in the periovulatory period relative to the nonfertile periods of the cycle, though the magnitude of this change may be subtle or dramatic. Nevertheless, even if the female ability to mate is no longer under hormonal control, its desire and then its decision to mate can be an important regulator of sexual behaviour, with females being able to exhibit more flexible responses to social and environmental contexts. For instance, copulations outside of the fertile period (and even during pregnancy, i.e. when there is no chance of conceiving) can be viewed as part of female sexual strategies to confuse paternity [80]. These post-conceptive sexual behaviours are expected to occur more often in species vulnerable to infanticide (e.g. Hanuman langurs, chimpanzees) than in species with low infanticide risks and/or living in harsh environments (e.g. Japanese macaques). In this latter species, females could indeed benefit from stopping copulations during pregnancy in order to avoid wasting energy on non-reproductive mating, decrease male harassment, and free resources to allocate to fetal growth (and not to mating costs). For males, giving up copulations during pregnancy could also provide some benefits as they do not waste energy in sperm production or in active mate-guarding of pregnant females. 
The cognitive mechanisms underlying partner choice and socio-sexual behaviours might often be complex. First, even if females could use reflexes based on sexually dimorphic male ornaments, the critical influence of social interactions on female reproductive success strongly suggests that they would not be sufficient to provide a reliable estimate of the costs and benefits associated with their potential choices. Second, even if hormonal changes are associated with mating behaviour, female primates probably need to mobilize complex and context-dependent mental representation of the social and reproductive value of their potential partner to selectively interact and plan their mating/association decisions, as we saw above for males. These processes involve a myriad of brain regions, and their implication in complex social interactions has raised a strong interest in recent years [22, 81]. However, there remains gaps in our understanding of the cerebral bases underlying social/sexual partner choice and the question of a) the level of cognitive complexity required to track previous exchanges with partners and compare simultaneously the relative value of the different benefits provided by each potential partner, and b) whether all primates possess these enhanced cognitive skills, for instance in terms of memory and ability to quantify, remain to be clarified and represent a critical but challenging avenue for future research in natural settings (as tested in the laboratory with ad hoc cognitive tasks).

\section{WHAT ABOUT HUMAN AND EXTINCT HOMININ MATING MARKETS?}

When it comes to humans and extinct hominins, the question of how cultural variation will affect "biological" and "economic" partner choice necessarily emerges. As in most non-human primates, mating markets in humans are influenced by environmental factors and are characterized by both sexes exerting preferences and having several partners to choose from simultaneously. Women make tradeoffs between male genetic quality and parental investment and men adjust their mating tactics to the behaviour of women [82]. Thereby, in an environment requiring biparental care where male parenting qualities are needed and valued, women would place more weight on the investment potential of prospective mates and less weight on indicators of their genetic fitness, with a larger proportion of women adopting long-term mating tactics almost exclusively. In response to this, males should devote greater effort to parental investment and variance in men's reproductive success should be reduced. On the other hand, in an environment where men's genetic fitness is more needed and valued (e.g. pathogen-prevalent environment), women should be more willing to engage in short-term matings, and consequently, men should devote greater effort to short-term and extra-pair mating. Indeed, women could benefit from polyandry under certain circumstances [83] and there are some evidence showing that the range of variation in extra-pair paternity across human populations is substantially greater than previously thought [84]. In some contexts, men may be choosing to provide care for non-biological children as part of the duties of social fatherhood in return for greater security for their own children or the benefits of strong male alliances [85]. Other examples in which women adjust their mating tactics come from studies focusing on women's control of resources (see review in [82]). Thereby, women's ability to accumulate wealth in modern cash economies could be less important than their access to power in the adjustment of their mating strategies [86, 87], which can mirror the influence that social hierarchy can have on mating tactics in non-human primate societies. Nevertheless, as adding wealth is likely to have direct reproductive benefits, i.e. increased fertility and reduced mortality of mother and child [88], economic considerations still play an important role in human partner choice for both sexes. 
Regarding extinct hominins, it is difficult to have a comprehensive picture of their mating systems and to infer mating behaviours and mate choices because they do not leave direct evidence in the fossil record. However, anatomical (e.g. sexual dimorphism) and cultural (e.g. stone artefacts) markers of life history and behavioural patterns can help to infer the social structure and/or mate choice of some extinct hominin species.

Sexual dimorphism, and especially canine height dimorphism, is often used to infer extinct hominin mating system (e.g. [89]). Among mammals, a low level of sexual dimorphism is often associated with monogamy, which increases the coalitionary power of females in relation to unrelated males (e.g. [90]). Moreover, polygyny is suggested to have emerged with the Australopithecines and may have been due to enhanced male mate guarding of a small number of partners within multi-male/multi-female social groups [91]. However, a study on Ardipithecus ramidus (4.4 Ma) [92] and statistical models of Australopithecus afarensis (3.8-3.1 Ma) sexual dimorphism [93] showed that these species had reduced sexual dimorphism and canine height. These findings suggest a strong decrease in the intensity of malemale competition and that these species already had a monogamous mating system. This transition to strong pair-bonding could have opened a path to higher male parental investment [94]. For Homo erectus sensu lato, two models have been proposed to explain their social organization, which could be then used to infer their mating system. The first one [95] proposes that the emergence of multi-level societies with male and female bonding [90] (observed in extant hamadryas baboons for example) could have characterized this taxa. According to this model, multi-level societies in extinct hominins would have increased benefits for both sexes in terms of reproduction, feeding, and protection of the offspring. Indeed, bonds between females would have been highly beneficial, as they would have allowed some cooperative foraging and breeding which can decrease the individual costs [96, 97]. Regarding males, the variable spatial distribution of females Homo erectus at least seasonally, may have placed selective pressures on them to become the resident or the alpha male of small groups [94] and to keep track of a limited number of females to facilitate mating access. The benefit to males is an exclusive access to mates and a better chance to obtain female sexual fidelity and paternity certainty. Moreover, the fact that the male stays in the group carries benefits for both sexes via protection from infanticide. An alternative model, the large fission-fusion society [80], has been proposed for Homo erectus, assuming that this species was living in chimpanzee-like fission-fusion groups, with immigrant females and a large number of bonded males. Fissions represent an opportunity to flexibly adjust behaviours and to recalibrate the trade-offs that individuals experience by living in groups. For instance, females are suggested to spread out when resources become scarce in order to reduce feeding competition, but when food is abundant they can forage together and aggregate, which could incur some benefits in terms of food access and ultimately in reproductive advantages. Willems and van Schaik [98] also suggested that Homo erectus lived in very large groups with many males, which gives the opportunity to cooperatively defend the group against carnivore predators, and could be beneficial for both sexes.

If sexual dimorphism has been often used to infer hominin mating system, it was also shown that facial dimorphism can be an indicator of mate choice. Indeed, according to several studies [99-101], the facial features and facial symmetry are major targets of selective mate choice. Thereby, females with child-like 
faces would be more attractive to males, whereas males with high cheekbones or strong jaws, which are testosterone-dependent features, would be preferred for copulation [100]. Like in other primates (see above section on female perspectives), it seems that female hominin mating decisions could have been linked to sexual dimorphic ornaments. As enlarged cheek-bones are linked to attractiveness in humans (e.g. [102]), Weston et al. [103] proposed that the evolution of a broad face (e.g. zygomatic region) and the loss of large canines in hominin males result from sexual selection operating mainly through mate choice. Besides morphological targets of selective mate choice, Kohn and Mithen [104] have proposed that acheulean handaxes, i.e. stone manufactured artefacts, which were found during the Pleistocene (first occurrence at $1.76 \mathrm{Ma}$ ) and often associated with Homo erectus sensu lato, could be considered as sexual ornaments and reliable indicators of a potential mate's quality that females could have used to make their mating decisions.

In conclusion, like in extant primates, different social and mating systems have been proposed depending on the hominin taxa. As for extant primates, male and female hominins presumably relied upon cognitive operations to make appropriate mating decisions, rather than upon reflexes. Indeed, these decisions probably involved complex and context-dependent mental representations of the reproductive and social value of their partners. This implies abilities in terms of decision-making and planning, which were likely highly developed in extinct hominins, presumably at an intermediate level between modern monkeys and humans, and sharing some similarities with modern apes. Indeed, such processes involve some regions of the prefrontal cortex (e.g. frontal pole, dorsal prefrontal cortex), which are characterized by an exceptional expansion in both human and great apes, with the origin of this enlargement being estimated at the root of great apes (19-15 Ma) [105].

\section{BALANCING COSTS AND BENEFITS AT THE COLLECTIVE LEVEL}

\section{Meat resources and hunting}

According to the "Optimal Foraging Theory" [106], animals should optimize their energetic balance while foraging, i.e. maximize benefits (energy intakes) and minimize costs (time costs and energy expenditure for accessing or manipulating food). It is generally accepted that virtually all primates engage cognitive operations to approach maximum foraging efficiency [107, 108]. Indeed, given the distribution of their food in space and time, they could not rely on simple rules (e.g. random search) or reflexes (e.g. approach food). Primate foraging strategies depend upon species (e.g. energy maximizers or time minimizers), individuals (based on their needs, age, reproductive state, etc. [109]), but also upon social factors such as intra-, inter-group or inter-species competition and predation [110, 111]. To optimize their energetic balance (see review in [112]) while dealing with the inherent competition with co-feeders, primates must flexibly and rapidly adjust their foraging strategies, which is thought to involve cognitive processes [112]. Following Garber et al. [111], primates would integrate both social and ecological information with a set of "decision rules", i.e. information being organized hierarchically with the most important information for that decision being given the largest weight. For example, species living in large social groups should be particularly sensitive to information about quantity, whereas species with a specialist diet would be particularly sensitive to information about food type. Comparatively, spatial and temporal information might have less weight on decisions. These decisions 
rules should thus be characteristic of a given species, but will also depend on individual variables (e.g. social rank, sex, age) and their changes over time. The complexity of the set of rules, together with the level of metacognitive control with which these rules are supervised and potentially adjusted online, should be closely associated with the level of cognitive sophistication, and potentially with the level of brain development of each animal.

In specific foraging contexts such as social predation (hunting in group), specific cognitive skills such as metacognition, traditionally associated with complex social interactions (e.g. theory of mind), presumably play a crucial role [14]. Indeed, social hunting, which is developed only in a few primate lineages such as chimpanzees, capuchins and hominins, requires that multiple individuals synchronize their moves or coordinate in space (see [113] to distinguish between various kinds of social hunting: synchrony, coordination and collaboration), with the prey being generally shared after successful capture. Hunting is mainly pursued by males, but even if the likelihood and success rate of social hunts generally increase with the number of male participants in most chimpanzee and capuchin populations, there is no clear tendency regarding the meat obtained per capita when the number of hunters increase [80], i.e. the individual benefits. One can therefore wonder what drives the individual decisions to engage in social hunting, what are the trade-offs involved in such decision-making processes, and why social hunting (with food transfer) evolved in so few of the meat-eating primate species.

There has been much debate over the putative social benefits of hunting [114-116], with social hunting being more frequent in male-bonded species, which creates the tolerance and trust allowing social capture and selective transfer with allies. In this context, social hunts could be a major way to cement social bonds, and then to positively affect individuals' fitness [22]. However, the social value of hunting could also rely upon the nutritional value of the meat [117], i.e. energy-rich diet, with meat being used as an exchange commodity or reward. Most research indeed suggests that meat is a concentrated source of vitamins, minerals and other essential micronutrients that are beneficial for an individual, even in small quantities $[118,119]$. In chimpanzees for example, the valuable micronutrients contained in meat $[117,120]$ could complement a predominantly plant-based diet, with a small amount of meat representing a favourable payoff. Moreover, the proteins from vertebrates tend to be of higher quality, due to favourable ratios of essential amino acids relative to plant foods [121]. For all these reasons, if the likelihood of obtaining meat increases with the number of hunters, then social predation would be nutritionally profitable.

Nevertheless, hunting is also costly and dangerous. Indeed, the chase of a fast and arboreal prey is arguably energetically expensive [118], and entails considerable risk, in terms of failure, falling, and injury [113, 122]. Moreover, consuming and processing raw meat can be time costly [123], as the gut of non-human primates, which is adapted to a primarily frugivorous and folivorous diet, may not be very efficient in this context. Thereby, feeding on meat can be considered as "high-risk, high-yield", with primates facing the packaging problem, which is, as described by Altmann [124], the fact that "Costs and benefits - good and bad - always come packaged together...No perfect food exists". According to the "Optimal Foraging Theory", hunting primates should therefore feed on prey that offer the highest ratio of benefits/costs, which depends upon various intrinsic, demographic and environmental conditions. 
These conditions include: 1) seasonality: hunting may not be optimal when other valuable and less costly items are present, e.g. fruit availability affects overall meat distribution and more individuals receive a share of the meat with decreasing levels of general fruit availability [125]; 2) opportunity: a hunt is more likely to succeed if many adult males are present; 3 ) individuals' energetic condition: individuals having a positive energy balance are more willing to target resources associated with high risk and high cost, which is typically the case for meat [122]. These several constraints, among others, could explain differences in hunting behaviours, frequencies, success rates and prey preferences (i.e. species, size), not only across primate species, but also across communities from the same species, and across individuals within a group. Regarding the differences between species, it seems that baboons [126] and bonobos (see references in [127]) hunt only occasionally, mainly because of the absence of strong male-male bonds in these species, even if some bonobo populations have been reported to consume meat at much higher rates than previously thought [127]. There are also differences across communities from the same species [128], with some possible socially transmitted differences in prey preferences [chimpanzees: 129].

At the group level, some sex differences have been reported in hunting behaviours and in the costs and benefits of hunting. Indeed, females are expected to be more risk-averse than males for two reasons. First, they should be more sensitive to food shortage because variation in female reproductive success is determined more by food access than by access to mates [55]. Second, females are often carrying young offspring, which incurs higher movement costs [130] and may reduce their ability to catch prey. It seems therefore that the hunting strategy followed by female non-human primates is similar to the ones used by women in hunter-gatherer populations, who typically target small and sedentary prey. Even if this strategy implies less energetic benefits, it also entails a reduction in risk (less exposure to predators and potential falls) and in the probability of failure [131].

Besides sex differences, the overall size of the group can also explain some differences, i.e. there is more hunting in larger groups with the hunting costs per hunter being expected to decrease as the number of hunters increases because it becomes more difficult for the prey to either escape or defend themselves [132]. Some individual behavioural tendencies have also been proposed to explain variation in hunting patterns within (and between) populations (and species), but also temporal variation in hunting frequency within groups [120]. Thereby, the fact that more hunting occurs in larger groups in chimpanzees can be partly explained by the presence of "impact hunters" [133], i.e. individuals with high hunting rates and whom the presence in a group makes hunting more likely both by their own efforts and by increasing the likelihood that others hunt. As shown by Gavrilets [134], those who contribute the most towards production of collective goods (i.e. hunt initiators) are those (i) who are particularly skilled, or (ii) for whom the benefits are especially high or (iii) for whom the costs are relatively low. They also create low-cost opportunities for others to benefit by joining a hunt in progress [120].

The mechanisms underlying these joint acts might be relatively complex. Gaze-following (i.e. orienting attention in the same direction as another individual) and joint attention could be critical for coordinating actions among hunters, and as discussed above, cognitive processes including 
metacognition and theory of mind are probably involved to support complex and dynamic interactions among individuals $[81,14,135]$. Besides coordination, group hunting presumably also implies planning, which is thought to be critical not only for hunting per se but also for hunt patrols, i.e. pre-hunt searches for prey (highly coordinated activities, during which individuals travel cohesively, with frequent pauses and rarely forage or vocalize [125]). Indeed, these patrols, that usually indicate an upcoming hunt, are initiated hours prior to hunt attempts, which implies not only planning but also coordination among future hunters $[113,136]$.

At the neurophysiological level, hunting behaviours could imply the oxytocinergic system. Indeed, joint actions activate areas of the brain associated with the processing of reward, and these behaviours are facilitated by oxytocin [22]. Several studies also showed that oxytocin could enhance cooperation and coordination in joint group activities, such as hunting parties [125, 137, 138]. However, it remains unclear whether oxytocin acts directly on coordination (i.e. relatively high-level processes) or indirectly, on lower level processes such as tolerance or vigilance, which are also critical for participation in joint group activities. The neural circuits mediating the behavioural and cognitive actions of oxytocin also remain unclear. At the cortical level, hunting presumably involves a myriad of structures since it implies numerous levels of behavioural and cognitive control. As discussed above, these cognitive processes include: 1) planning and working memory (known to rely upon the dorso-lateral prefrontal cortex and the parietal cortex [9]); 2) context-dependent representation of the goal value (known to rely upon the ventromedial prefrontal cortex [6-7]); 3) cognitive control and the computation of the costs/benefits trade-off (known to involve the anterior part of the cingulate cortex [10, 139]); 4) a form of metacognition to allow coordination and planning at the group level [135, 140]. Further work is necessary to accurately identify the neuro-cognitive processes underlying group hunting in primates. Besides classical laboratory approaches with captive animals performing specific cooperative tasks mimicking social hunting that would allow to dissect these processes very precisely, neuroanatomical comparisons across species in which the behavioural and ecological components of hunting have been well identified (as in [141] for foraging behaviours in general) could also shed light upon the neurocognitive bases of group hunting.

\section{Hunting in extinct hominins and humans}

Understanding the relative benefits and costs of acquiring and consuming different forms of animal matter by extant primates is also critical for identifying the selective pressures responsible for increased meat consumption in the hominin lineage.

Meat has been exploited by hominins for at least 2 million years using at the beginning confrontational scavenging by driving large carnivores from their prey. Hominins, especially after $2 \mathrm{Ma}$ (e.g. Homo erectus sensu (ato), had a small gut which is required to efficiently process food of low digestibility, such as meat [142]. The energetic content of meat is suggested to have critically influenced the evolution and the maintenance of birth rate, body size, and brain size (e.g. [142-144]) and costly activities such as endurance running. 
One step further may have involved the use of processing methods, such as pounding (e.g. [145]), which occurred since the lower Pleistocene (around $2 \mathrm{Ma}$ ) and even earlier at 3.3 Ma. This could have provided an important increase in energy gain over unprocessed raw diets. Lithic tool-kits may have been highly beneficial in allowing extinct hominins to have access to fleshed carcasses, with cutting edges for processing soft tissue, which was not possible with their masticatory apparatus (reduced prognathism and relatively small incisors and canines), as well as percussion tools to extract the marrow. If the first archaeological evidence of stone tool-making [146] and stone tool-using [147] is dated to 3.4-3.3 Ma, the tool-kits have been growing in terms of complexity after 2.3 Ma. Plio-Pleistocene hominins used stone cutting tools for pre-oral food processing, which requires to collect raw material and extract flakes bearing sharp cutting edges from raw material, and then probable remarkable cognitive and motor abilities. Through time, there was an increase in raw material transportations distance in order to find the most efficient one and an intensification of processing of animal tissues including meat and marrow extraction. These processes probably involved an increase in the level of decision-making and planning. But eating scavenged meat could also be highly dangerous, as the carrion could have been contaminated by bacteria. However, this cost could have been reduced by selecting only the marrow (where fewer bacteria grow), by eating the freshly-killed carcass or by cooking it [148].

Cooking, initially very occasional using for example hot springs, could have occurred with Homo erectus in Africa (ca. 1.9 million years ago) [149]. However, the oldest evidence of intensive and habitual cooking, based on archaeological evidence and comforted by genetic analyses, is from the middle Pleistocene (300-400,000 years ago), suggesting that this behaviour is relatively recent (e.g. [150]), i.e. human adaptation to a cooked diet had begun before the split between modern humans, Neanderthals and Denisovian (at least 275,000 years ago) [151]. Cooking facilitates the mastication, kills food pathogens, induces a rise in the energetic gain of the meat, including an increased energy extraction per unit mass compared with raw food and increased digestibility value of proteins, a reduction in the costs of digestion, and a modification in the speed of meat protein digestion (e.g. [152-154]). It also raises glutamate and sugar availability, appreciated by primates (e.g. humans, chimpanzees and gorillas), who seem to prefer cooked food to raw food in captivity $[155,156]$. Cooking also induces amino acid residue level modifications which contribute to advantageous traits in a food product (e.g. formation of peptide which are resistant to further break down into free amino acids by digestive enzymes; [157]). However, the adoption of cooking also comes with some costs in terms of loss of vitamins (as vitamin C) and of delay before the consumption of the food, which is brought to the processing area or stored.

The control of fire for cooking, but also for boiling and smoking the foods to preserve them, was firstly evidenced 790,000 years ago in the Near East and 450,000 years in Europe [158]. This control is beneficial as it provides light, heat, protection against the predator and comes with technical progress (e.g. preparation of resins or improvement of knapping capacities of certain raw material or hardening of wooden spear). But, the control of fire is also cognitively demanding because it requires a considerable amount of knowledge about the environment, ranging from the collection of fuel (choice of wood, bones, plants, minerals, stones, etc.), the implantation of the fireplace (stone structure, dug pit, location, orientation, etc.) to its lighting and maintenance. 
Cooperative (i.e. social) hunting using exhaustion pursuit occurred quite early in hominin evolution (lower Pleistocene, around 1.8 Ma). According to Van Schaik [80], the model of fusion-fission proposed for Homo erectus sensu lato could explain the origin of cooperative hunting followed by the sexual division of labour. Moreover, the morphological features associated to endurance running in early Homo have been suggested to enable them to practice persistence (long-distance pursuit) hunting, i.e. chasing an animal until it reaches exhaustion potentially during the hottest time of the day, thus driving prey into hyperthermia [159-161]. However, chasing prey for extended periods of time in hot temperatures is also obviously energetically demanding, and could have represented a substantial energetic cost in early Homo, even for chasing medium sized prey [162]. Therefore, the persistence hunting is obviously critical for the cost/benefit balance and cooperative strategies associated with persistence hunting might have greatly reduced the costs encountered at an individual level.

The costs and benefits of cooperative hunting could have differed depending on the size of the game. Hunting small and fast game (birds, leporids) had low risk of injury and could have provided some fur (which can be used for clothing by hominins in high latitudes during cold seasons) and some raw material for ornaments (e.g. eagle bones). However, it provided a small amount of meat per prey. Hunting big game could have been energetically more expensive with high risk of injury and risk of failure, but the amount of meat to share could have been considerable. Cooperative big game hunting may necessitate an organization of work force to plan goal to acquire large animals and bring them back to the camp, with this cooperation reducing the risk of failure. Complex forms of cooperative hunting using weapons (e.g. wooden spear, throwing stick), which require advanced planning in terms of manufacture and use, emerged around $300 \mathrm{ka}$ [163]. When weapons systems allowed to hunt prey from a long distance, the risk of injury was reduced and the role of women as hunters increased [164]. According to Kuhn and Stiner [164], Neanderthal females and juveniles participated in the hunting of large terrestrial game. Neanderthals were faced with the dilemma of improving the extractive benefits (with the participation of women or old juveniles in hunting) and minimizing the survival risk to their offspring due to the danger.

In modern hunter-gatherers populations, hunting is also conducted in groups, which implies a regulation of costs and benefits at the population level. In most cases, the meat of large animals is widely shared with a meat-to-meat repayment. The cost of sharing is quite low, since the amount of meat is greater than what each hunter and his family can eat at one time. Sharing also reduces the cost of storing such a large amount of meat, which could quickly get spoiled. At the population level, the benefits of repayment are quite high as it reduces the probability of meat shortfalls for individuals. However, this type of meat-to-meat transfer is not found in all hunter-gatherer populations, with hunters in Hadza populations (organized in bands with no governing hierarchy [165]) being rather repaid in another currency than foods (e.g. other goods or services). In these populations, the carcass is more like a public good and the hunters do not control its distribution. Therefore, the hunter has no family provisioning insurance and this does not reduce his daily risk of failing to supply food to his household. Nevertheless, it has been shown that even if hunters do not get more meat repayment for their own families, they acquire a better hunting reputation, enhance their status as desirable neighbours [165], and have some reproductive benefits, i.e. higher fertility and reproductive success (e.g. [166]). 
Meat consumption and hunting are therefore major evolutionary changes in the hominin diet and subsistence behaviour. They serve a social as well as a nutritional purpose, with hunting being an indicator of leadership qualities for early human groups but also for extant primates. There is a great diversity in hunting behaviours across primate and extinct hominin species, but also across communities of the same non-human primate species, or across hunter-gatherers populations (e.g. division of labour in some of them but not in all). If extant primates and extinct hominins present some similarities for meat acquisition, there are still some differences, notably in terms of the size of the prey and of the processes used to acquire meat. Through time, meat has been exploited by hominins first by confrontational scavenging, followed by cooperative hunting using exhaustion pursuit, and ultimately by a more complex form of cooperative hunting using weapons, with a division of labour in the most recent populations. Regarding extant primates, confrontational scavenging has been rarely reported [167] and social hunting seems to be less frequent than in the hominin lineage. The complex form of cooperative hunting with weapons and the division of labour, as well as processing techniques (e.g. pounding and cooking), appear to be unique to hominins, and could have allowed them to maximize the ratio benefits/costs of this foraging strategy.

As we saw above for extant primates, social/cooperative hunting most probably implies well-developed metacognitive skills, and early hominins, like modern humans and chimpanzees, were very likely to possess such skills. Like social hunting, stone-tool making and cooking (only in hominins) imply a very high level of planning and metacognition because it requires complex causal inferences and very distant and indirect benefits. Indeed, cooking implies multiple steps that need to be coordinated and such complex goals are thought to involve high-level recursive planning. Likewise, manufacturing stone-tools (unique to hominins) implies building a representation of the tool (the direct goal) as well as a higher representation of how the tool would be used, i.e. in a very distinct context and time frame compared to its manufacture.

\section{Conclusion}

In conclusion, extant primates (including humans) and extinct hominins are suggested to show some behavioural plasticity that enables them to respond optimally to rapidly changing environments. Natural selection has favoured individuals that are equipped with the cognitive canvas to make efficient decisions about the management of multiple resources (e.g. food, services, partners), both at the individual and at the group level, in order to regulate the balance between the costs and benefits for accessing the goal (e.g. mating with a chosen partner, hunting a prey). In most situations, costs and benefits come together as 'packages' such that, rather than trying to maximize the cost/benefit ratio in the absolute sense, most primates presumably use cognitive skills to identify the best of the potential packages, given the context. Nevertheless, these packages do not come as discrete independent options. Rather, in their natural environment, primates must coordinate multiple needs and potential plans of actions, and manage a constant flux of information from the environment. Moreover, as other long-lived species, they need to navigate a social world in which they must base their decisions not only on the current behaviours of the other group-members, but also on the history of the previous interactions with those individuals. This implies to recognize not only other individuals' relative rank and 
social relationships, but also the nature and quality of recent interactions and the value of particular partners. Thereby, they have probably developed a set of cognitive skills (e.g. episodic memory, valuebased decision making, planning) to make adaptive decisions, such as choosing partners based on the expected benefits (based on past and ongoing interactions) they could provide, and selecting options that fulfil not only individual needs but also collective needs (e.g. hunting and meat transfer) that should allow supplying future individual needs. Evidence from the archaeological and fossil record suggest that, early in the evolutionary history of primates, selection should have favoured the development of cognitive mechanisms that shaped these economic behaviours. These evolutionary developments were further refined across hominins and enabled them to handle packages of increasing costs and benefits. Distinct extinct hominins and extant primate species developed specific sets of solutions based on their needs and environmental constraints as well as opportunities, and more studies are still needed to shed light on the complexity and diversity that can be found in primates making adaptive decisions related to the optimization of benefits and costs.

\section{Acknowledgments}

We thank Elsa Addessi, Thomas Boraud and Sacha Bourgeois-Gironde for their invitation to contribute to this special issue on Existence and prevalence of economic behaviours among non-human primates. We also thank the reviewers and the editors for their constructive comments that helped improving the manuscript. S.P. thanks the ANR-17-CE27-005 for support.

\section{REFERENCES}

1. Noë R, Hammerstein P. 1994 Biological markets: supply and demand determine the effect of partner choice in cooperation, mutualism and mating. Behav. Ecol. Sociobiol. 35, 1-11. (doi:10.1007/BF00167053)

2. Fruteau C, Voelkl B, van Damme E, Noë R. 2009 Supply and demand determine the market value of food providers in wild vervet monkeys. Proc. Natl. Acad. Sci. U S A. 106, 12007-12. (doi: 10.1073/pnas.0812280106)

3. Hammerstein P, Noë R. 2016 Biological trade and markets. Philos. T. R. Soc. B 371, 20150101. (doi:10.1098/rstb.2015.0101)

4. Bolhuis JJ, Giraldeau, L. 2005 The Behavior of Animals: mechanisms, function and evolution. Blackwell Publishing Ltd, Oxford, UK.

5. Balleine BW, Dickinson A. 1998 Goaldirected instrumental action: contingency and incentive learning and their cortical substrates. Neuropharmacology. 37, 407-19. (doi: 10.1016/s0028-3908(98)00033-1.)

6. Barron HC, Dolan RJ, Behrens TEJ. 2013 Online evaluation of novel choices by simultaneous representation of multiple memories. Nature Neuro. 16, 1492-1498. (doi:10.1038/nn.3515)

7. Lebreton $\mathrm{MI}$, Bertoux $\mathrm{M}$, Boutet $\mathrm{C}$, Lehericy $S$ et al. 2013 A Critical Role for the Hippocampus in the Valuation of Imagined Outcomes. PLoS Biol. 11, e1001684. (doi:10.1371/journal.pbio.1001684.s002)

8. Boureau YL, Sokol-Hessner P, Daw ND. 2015 Deciding How To Decide: Self-Control and Meta-Decision Making. Trends Cogn. Sci. 19, 700-710. (doi: 10.1016/j.tics.2015.08.013)

9. Fuster JM. 2015 The Prefrontal Cortex. Academic Press. (doi:10.1016/C2012-0-061649)

10. Shenhav A, Musslick S, Lieder F, Kool W et al. 2017 Toward a Rational and Mechanistic Account of Mental Effort. Annu. Rev. Neurosci. 40, 99-124. (doi:10.1146/annurevneuro-072116-031526)

11. Janson C. 2016 Capuchins, space, time and memory: an experimental test of what-where when memory in wild monkeys. Proc. Roy. Soc. B 283, 20161432. (doi: $\underline{10.1098 / \text { rspb.2016.1432) }}$
12. Clayton NS, Bussey TJ, Dickinson A. 2003 Can animals recall the past and plan for the future? Nat. Rev. Neurosci. 4, 685.

13. MacLean EL, Merritt DJ, Brannon EM. 2008 Social Complexity Predicts Transitive Reasoning in Prosimian Primates. Anim. Behav. 76, 479-486. (doi:10.1016/j.anbehav.2008.01.025)

14. Devaine M, San-Galli A, Trapanese C, Bardino et al. 2017 Reading wild minds: A computational assay of Theory of Mind sophistication across seven primate species. PLoS Comput. Biol. 7, 1005833. (doi: 10.1371/journal.pcbi.1005833).

15. Rosati AG. 2017 Foraging Cognition: Reviving the Ecological Intelligence Hypothesis. Trends Cogn. Sci. 21, 691-702. (doi:10.1016/j.tics.2017.05.011)

16. Cheney DL, Seyfarth RM. 2007 Baboon Metaphysics: Evolution of a Social Mind. University of Chicago Press.

17. Brockman DK, van Schaik CP. 2005 Seasonality and reproductive function. In "Seasonality in Primates: Studies of Living and Extinct Human and Non-Human Primates" (D.K. Brockman, C.P. van Schaik, Eds), pp 269305. Cambridge University Press, Cambridge. 
18. Garcia C, Shimizu K, Huffman M. 2009 Relationship between sexual interactions and the timing of the fertile phase in captive female Japanese macaques (Macaca fuscata). Am. J. Primatol. 71, 868-879. (doi: 10.1002/ajp.20717)

19. Schülke O, Heistermann M, Ostner J. 2014. Lack of Evidence for Energetic Costs of MateGuarding in Wild Male Assamese Macaques (Macaca assamensis). Int. J. Primatol. 35, 677-700. (doi:10.1007/s10764-013-9748-y)

20. Sen AK, Smith TE. 1995 Gravity Models of Spatial Interaction Behavior. Springer Verlag, Berlin.

21. Minamimoto $T$, La Camera G, Richmond BJ. 2009 Measuring and modeling the interaction among reward size, delay to reward, and satiation level on motivation in monkeys. J. Neurophysiol. 101, 437-447. (doi: 10.1152/jn.90959.2008)

22. Platt ML, Seyfarth RM, Cheney DL. 2016 Adaptations for social cognition in the primate brain. Philos. T. R. Soc. B 371, 20150096. (doi:10.1098/rstb.2015.0096)

23. Cheney DL. 2011 The extent and limits of cooperation in animals. P. Natl Acad. Sci. USA 108, 10902-10909. (doi:10.1073/pnas.1100291108)

24. Alberts SC, Altmann J, Wilson ML. 1996 Mate guarding constrains foraging activity of male baboons. Anim. Behav. 51, 1269-1277. (doi: 10.1006/anbe.1996.0131)

25. Dixson AF. 2012 Primate Sexuality: Comparative Studies of the Prosimians, Monkeys, Apes, and Humans. Oxford University Press, Oxford.

26. Girard-Buttoz C, Heistermann M, Rahmi E, Marzec A et al. 2014 Mate-guarding constrains feeding activity but not energetic status of wild male long-tailed macaques (Macaca fascicularis). Behav. Ecol. Sociobiol. 68, 583-595. (doi:10.1007/s00265-013-16738)

27. Andersson M. 1994 Sexual selection. Princeton University Press, Princeton, New Jersey.

28. Dominey WJ. 1984 Alternate mating tactics and evolutionarily stable strategies. Am. Zool. 24, 85-96.

29. Girard-Buttoz C, Heistermann M, Rahmi E, Agil M et al. 2014 Costs of mate-guarding in wild male long-tailed macaques (Macaca fascicularis): physiological stress and aggression. Horm. Behav. 66, 637-648. (doi: 10.1016/i.yhbeh.2014.09.003)

30. Fürtbauer I, Heistermann M, Schulke O, Ostner J. 2011. Concealed fertility and extended female sexuality in a non-human primate (Macaca assamensis). PLoS One 6, e23105. (doi: 10.1371/journal.pone.0023105)

31. Girard-Buttoz C, Heistermann M, Rahmi E, Agil M et al. 2014 Costs of and Investment in Mate-Guarding in Wild Long-Tailed Macaques (Macaca fascicularis): Influences of Female Characteristics and Male-Female Social Bonds. Int. J. Primatol. 35, 701-724. (doi:10.1007/s10764-014-9775-3)

32. Wingfield JC, Hegner RE, Dufty AM Jr, Ball GF. 1990 The "challenge hypothesis": Theoretical implications for patterns of testosterone secretion, mating systems, and breeding strategies. Am. Nat. 136, 829-846. www.jstor.org/stable/2462170.

33. Muller MN. 2017 Testosterone and reproductive effort in male primates. Horm. Behav. 91, 36-51. (doi:10.1016/j.yhbeh.2016.09.001)

34. Onyango PO, Gesquiere LR, Altmann J, Alberts SC. 2013 Testosterone positively associated with both male mating effort and paternal behavior in savanna baboons (Papio cynocephalus). Horm. Behav. 63, 430-436. (doi:10.1016/j.yhbeh.2012.11.014)

35. Kalbitzer U, Heistermann M, Cheney D, Seyfarth R et al. 2015 Social behavior and patterns of testosterone and glucocorticoid levels differ between male chacma and Guinea baboons. Horm. Behav. 75, 100-110. (doi:10.1016/i.yhbeh.2015.08.013)

36. Schoof VAM, Jack KM, Ziegler TE. 2014 Male response to female ovulation in whitefaced capuchins (Cebus capucinus): Variation in fecal testosterone, dihydrotestosterone, and glucocorticoids. Int. J. Primatol. 35, 643660. (doi: 10.1007/s10764-013-9742-4)

37. Muller MN, Wrangham RW. 2004 Dominance, aggression and testosterone in wild chimpanzees: A test of the "challenge hypothesis". Anim. Behav. 67, 113-123. (doi:10.1016/i.anbehav.2003.03.013)

38. Girard-Buttoz C, Heistermann M, Rahmi E, Agil M et al. 2015 Androgen correlates of male reproductive effort in wild male longtailed macaques (Macaca fascicularis): A multi-level test of the challenge hypothesis. Physiol. Behav. 141, 143-153. (doi:10.1016/j.physbeh.2015.01.015)

39. Goymann W, Landys MM, Wingfield JC. 2007 Distinguishing seasonal androgen responses from male-male androgen responsiveness - revisiting the challenge hypothesis. Horm. Behav. 51, 463-476. (doi: 10.1016/j.yhbeh.2007.01.007)

40. Bercovitch FB. 1997 Reproductive strategies of rhesus macaques. Primates 38, 247-263.

41. Engelhardt A, Heistermann M, Hodges JK, Nürnberg $\mathrm{P}$ et al. 2006 Determinants of male reproductive success in wild long-tailed macaques (Macaca fascicularis) - male monopolisation, female mate choice or postcopulatory mechanisms? Behav. Ecol. Sociobiol. 59, 740-752. (doi:10.1007/s00265005-0104-x)

42. Matsubara M. 2003 Costs of mate guarding and opportunistic mating among wild male Japanese macaques. Int. J. Primatol. 24, 1057-1075. (doi: 10.1023/A:1026228312706)

43. Setchell JM, Charpentier MJE, Wickings EJ. 2005 Mate guarding and paternity in mandrills: factors influencing alpha male monopoly. Anim. Behav. 70, 1105-1120. (doi:10.1016/j.anbehav.2005.02.021)

44. Delville Y, Mansour KM, Ferris CF. 1996 Testosterone facilitates aggression by modulating vasopressin receptors in the hypothalamus. Physiol. Behav. 60, 25-29. (doi: 10.1016/0031-9384(95)02246-5)

45. Van Noordwijk MA, van Schaik CP. 1999 The effects of dominance rank and group size on female lifetime reproductive success in wild long-tailed macaques, Macaca fascicularis. Primates 40, 105-130. (doi: 10.1007/BF02557705)

46. Majolo B, Lehmann J, Vizioli A. de B, Schino G. 2012 Fitness-related benefits of dominance in primates. Am. J. Phys. Anthropol. 147, 652-660. (doi: 10.1002/ajpa.22031)

47. Muller MN, Thompson ME, Wrangham RW. 2006 Male chimpanzees prefer mating with old females. Curr. Biol. 16, 2234-2238. (doi: 10.1016/j.cub.2006.09.042)

48. Setchell JM, Wickings EJ. 2006 Mate choice in male mandrills (Mandrillus sphinx). Ethology 112, 91-99. (doi:10.1111/j.14390310.2006.01128.x)

49. Smuts BB. 1985 Sex and Friendship in Baboons. Aldine de Gruyter, Hawthorne, New York.

50. Chapais B. 1983 Reproductive activity in relation to male dominance and the likelihood of ovulation in rhesus monkeys. Behav. Ecol. 
Sociobiol. 12, 215-228. (doi: $\underline{10.1007 / B F 00290774)}$

51. Takahata Y. 1982 The socio-sexual behavior of Japanese monkeys. J. Comp. Ethol. 59, 89-108. (doi: 10.1111/i.14390310.1982.tb00332.x)

52. Engelhardt A, Pfeifer JB, Heistermann M, Niemitz C et al. 2004 Assessment of female reproductive status by male longtailed macaques, Macaca fascicularis, under natural conditions. Anim. Behav. 67, 915-924. (doi: 10.1016/i.anbehav.2003.09.006)

53. Weingrill $\mathrm{T}$, Lycett JE, Barrett L, Hill RA et al. 2003 Male consortship behaviour in chacma baboons: The role of demographic factors and female conceptive probabilities. Behaviour 140, 405-427. (doi: $10.1163 / 156853903321826701$ )

54. Martinez G, Garcia C. 2020 Sexual selection and sperm diversity in primates. Mol. Cell. Endocrinol. 518:110974. (doi: 10.1016/j.mce.2020.110974).

55. Clutton-Brock TH. 2007 Sexual selection in males and females. Science 318, 1882-1885. (doi:10.1126/science.1133311)

56. Kappeler PM, van Schaik CP. 2004 Sexual selection in primates: new and comparative perspectives. Cambridge University Press, Cambridge.

57. van Schaik $C P$, Pradhan $G R$, van Noordwijk MA. 2004 Mating conflict in primates: infanticide, sexual harassment and female sexuality. In "Sexual Selection in Primates" (P.M. Kappeler, C.P. van Schaik, Eds), pp 131150. Cambridge University Press, Cambridge.

58. Muller MN, Emery Thompson $M$, Kahlenberg SM, Wrangham RW. 2011 Sexual coercion by male chimpanzees shows that female choice may be more apparent than real. Behav. Ecol. Sociobiol. 65, 921-933. (doi:10.1007/s00265-010-1093-y)

59. Muller MN, Kahlenberg SM, Emery Thompson M, Wrangham RW. 2007 Male coercion and the costs of promiscuous mating for female chimpanzees. Proc. Biol. Sci. 274, 1009-1014.

60. Lyon BE, Montgomerie R. 2012 Sexual selection is a form of social selection. Phil. Trans. R. Soc. B 367, 2266-2273. (doi: 10.1098/rstb.2012.0012)

61. Nikitopoulos $E$, Heistermann $M$, de Vries $\mathrm{H}$, van Hooff JARAM et al. 2005 A pair choice test to identify female mating pattern relative to ovulation in long tailed macaques, Macaca fascicularis, Anim. Behav. 70, 1283-1296. (doi:10.1016/i.anbehav.2005.03.006)

62. Rooker K, Gavrilets S. 2020 On the evolution of sexual receptivity in female primates. Sci. Rep. 10, 11945. (doi:10.1038/s41598-020-68338-y)

63. Koda H, Murai T, Tuuga A, Goossens B et al. 2018 Nasalization by Nasalis larvatus: Larger noses audiovisually advertise conspecifics in proboscis monkeys. Sci. Adv. 4: eaaq0250. (doi:10.1126/sciadv.aaq0250)

64. Setchell JM, Smith T, Wickings EJ, Knapp LA. 2008 Social correlates of testosterone and ornamentation in male mandrills. Horm.

Behav. 54, 365-372.

(doi:10.1016/j.yhbeh.2008.05.004)

65. Lewis RJ. 2009 Chest staining variation as a signal of testosterone levels in male Verreaux's Sifaka. Physiol. Behav. 96, 586592. (doi: 10.1016/j.physbeh.2008.12.020)

66. Waitt C, Little AC, Wolfensohn S, Honess P et al. 2003 Evidence from rhesus macaques suggests that male coloration plays a role in female primate mate choice. Proc. Roy. Soc. B. 270, S144-S146. (doi: 10.1098/rsbl.2003.0065)

67. Setchell JM. 2005 Do female mandrills (Mandrillus sphinx) prefer brightly coloured males? Int. J. Primatol. 26, 713-732. (doi: 10.1007/s10764-005-5305-7)

68. Haunhorst CB, Heesen M, Ostner J, Schülke O. 2017 Social bonds with males lower the costs of competition for wild female Assamese macaques. Anim. Behav. 125, 5160. (doi: 10.1016/j.anbehav.2017.01.008)

69. Lemasson A, Palombit RA, Jubin R. 2008 Friendships between males and lactating females in a free-ranging group of olive baboons (Papio hamadryas anubis): evidence from playback experiments. Behav. Ecol. Sociobiol. 62, 1027-1035. 〈doi: 10.1007/s00265-007-0530-z).

70. Menard N, von Segesser F, Scheffrahn W, Pastorini J et al. 2001 is male-infant caretaking related to paternity and/or mating activities in wild Barbary macaques (Macaca sylvanus)? C. R. Acad. Sci. 324, 601-610.

71. Ostner J, Vigilant L, Bhagavatula J, Franz M et al. 2013 Stable heterosexual associations in a promiscuous primate. Anim. Behav. 86, 623-631.

(doi:10.1016/i.anbehav.2013.07.004)

72. Nguyen N, Van Horn RC, Alberts SC, Altmann J. 2009 "Friendships" between new mothers and adult males: adaptive benefits and determinants in wild baboons (Papio cynocephalus). Behav. Ecol. Sociobiol. 63, 1331-1344. (doi:10.1007/s00265-009-0786-6)

73. Palombit RA. 2003 Male infanticide in wild savanna baboons: adaptive significance and intraspecific variation. In "Sexual Selection and Reproductive Competition in Primates: New Perspectives and Directions" (C.B. Jones, Ed), pp 367-412. American Society of Primatologists.

74. Zipple MN, Grady JH, Gordon JB, Chow LD et al. 2017 Conditional fetal and infant killing by male baboons. Proc. R. Soc. Lond. 284, 20162561. (doi: $10.1098 / \mathrm{rspb} .2016 .2561$ )

75. Städele V, Roberts ER, Barrett BJ, Strum SC et al. 2019 Male-female relationships in olive baboons (Papio anubis): Parenting or mating effort? J. Hum. Evol. 127, 81-92. (doi: 10.1016/j.jhevol.2018.09.003)

76. Barrett L, Henzi SP, Weingrill T, Lycett JE et al. 1999 Market forces predict grooming reciprocity in female baboons. Proc. Biol. Sci. 266, 665. (doi: 10.1098/rspb.1999.0687)

77. van Schaik CP, Paul A. 1996 Male care in primates: does it ever reflect paternity? Evol. Anthropol. 5, 152-156.

78. Buchan JC, Alberts SC, Silk JB, Altmann J. 2003 True paternal care in a multimale primate society. Nature 425, 179-181. (doi:10.1038/nature01866)

79. Moscovice LR, Di Fiore A, Crockford C, Kitchen DM et al. 2010 Hedging their bets? Male and female chacma baboons form friendships based on likelihood of paternity. Anim. Behav. 79, 1007-1015. (doi:10.1016/j.anbehav.2010.01.013)

80. van Schaik CP. 2016 The primate origins of human nature. Wiley-Blackwell, Hoboken, New Jersey.

81. Rushworth MF, Mars RB, Sallet J. 2013 Are there specialized circuits for social cognition and are they unique to humans? Curr. Opin. Neurobiol. 23, 436-442. (doi: 10.1016/j.conb.2012.11.013)

82. Gangestad SW, Simpson JA. 2000 The evolution of human mating: trade-offs and strategic pluralism. Behav. Brain Sci. 23:573587.

83. Scelza BA. 2013 Choosy but not chaste: Multiple mating in human females. Evol. Anthropol. 22, 259-269. (doi: 10.1002/evan.21373)

84. Scelza BA, Prall SP, Swinford N, Gopalan S et al. 2020 High rate of extrapair paternity in a human population demonstrates diversity in 
human reproductive strategies. Sci. Adv. 6, eaay6195. (doi: 10.1126/sciadv.aay6195)

85. Walker RS, Flinn MV, Hill KR. 2010 Evolutionary history of partible paternity in lowland South America. Proc. Natl. Acad. Sci. U.S.A. 107, 19195-19200. (doi: 10.1073/pnas.1002598107)

86. Buss DM. 1989 Sex differences in human mate preferences: Evolutionary hypotheses tested in 37 cultures. Behav. Brain Sci. 12, 114.

87. Eagly AH, Wood W. 1999 The origins of sex differences in human behavior: Evolved dispositions versus social roles. Am. Psychol. 54, 408-423.

88. Testart A. 2013 Reconstructing social and cultural evolution: The case of dowry in the Indo-European area. Curr. Anthropol. 54, 2350. (doi: $10.1086 / 668679$ )

89. Plavcan JM. 2000 Inferring social behavior from sexual dimorphism in the fossil record. J. Hum. Evol. 39, 327-344. (doi :10.1006/jhev.2000.0423)

90. Chapais B., 2013. Monogamy, Strongly Bonded Groups, and the Evolution of Human Social Structure. Evol. Anthrop. 22, 52-65. (doi :10.1002/evan.21345)

91. Dixson AF. 2009. Sexual selection and the Origins of Human Mating Systems. Oxford University Press, Oxford.

92. Lovejoy CO. 2009 Reexamining human origins in light of Ardipithecus ramidus. Science 326, 108-115. (doi :10.1126/science.1175834)

93. Reno PL, Meindl RS, McCollum MA, Lovejoy CO. 2003 Sexual dimorphism in Australopithecus afarensis was similar to that of modern humans. Proc. Natl. Acad. Sci. U S A. 100, 9404-9409 (doi:10.1073/pnas.1133180100)

94. Gavrilets S. 2012 Human origins and the transition from promiscuity to pair-bonding. Proc. Natl. Acad. Sci. U S A. 109, 9923-9928. (doi :10.1073/pnas.1200717109)

95. Swedell L, Plummer T. 2012. A papionin multilevel society as a model for hominin social evolution. Int. J. Primatol. 33, 11651193. (doi: 10.1007/s10764-012-9600-9)

96. Aiello LC, Key C. 2002 Energetic consequences of being a Homo erectus female. Am. J. Hum. Biol. 14, 551-565. (doi:10.1002/ajhb.10069)
97. O'connell JF, Hawkes K, Blurton Jones NG. 1999 Grandmothering and the evolution of Homo erectus. J. Hum. Evol. 36, 461-485. (doi:10.1006/jhev.1998.0285)

98. Willems EP, Van Schaik CP. 2017 The social organization of Homo ergaster: Inferences from anti-predator responses in extant primates. J. Hum. Evol 109, 111-121. (doi :10.1016/j.jhevol.2017.05.003)

99. Little AC, Jones BC, DeBruine LM. 2011. Facial attractiveness: evolutionary based research. Phil. Trans. R Soc. B 366, 16381659. (10.1098/rstb.2010.0404)

100. Miller GF. 1998. How mate choice shaped human nature: A review of sexual selection and human evolution. In "Handbook of evolutionary psychology: Ideas, issues, and applications" (C. Crawford, D. Krebs, Eds), pp 87-130. Lawrence Erlbaum.

101. Rowland HM, Burriss RP. 2017 Human colour in mate choice and competition. Philos. T. R. Soc. B 37, 20160350. (doi:10.1098/rstb.2016.0350)

102. Penton-Voak IS, Perrett DI, Castles DL, Kobayashi T et al. 1999 Menstrual cycle alters face preference. Nature 399, 741-742. (doi :10.1038/21557)

103. Weston EM, Friday AE, Johnstone RA, Schrenk F. 2004 Wide faces or large canines? The attractive versus the aggressive primate. Proc. R. Soc. B. (suppl.) 271, S416-S419. (doi:10.1098/rsbl.2004.0203)

104. Kohn M, Mithen S. 1999. Handaxes: products of sexual selection? Antiquity 73, 518-26. (doi :10.1017/\$0003598X00065078)

105. Smaers JB, Gomez-Robles A, Parks AN, Sherwood CC 2017 Exceptional Evolutionary Expansion of Prefrontal Cortex in Great Apes and Humans. Curr. Biol. 27, 714-720 (doi:10.1016/j.cub.2017.01.020)

106. Stephens DW, Krebs JR. 1986 Foraging Theory. Princeton University Press, Princeton, New Jersey.

107. Dall SR, Giraldeau LA, Olsson O, McNamara JMet al. 2005 Information and its use by animals in evolutionary ecology. Trends Ecol. Evol. 20, 187-193. (doi:10.1016/j.tree.2005.01.010)

108. Robbins MM, Hohmann G. 2006 Primate feeding ecology: an integrative approach. In "Feeding ecology in apes and other primates" (G. Hohmann, M.M. Robbins, C. Boesch, Eds). Cambridge University Press, Cambridge.
109. Rosetta L, Lee PC, Garcia C. 2011 Energetics during reproduction: a doubly labeled water study of lactating baboons. Am. J. Phys. Anthropol. 144, 661-668. (doi: 10.1002/ajpa.21475)

110. Barrett L, Halliday J, Henzi SP. 2006 The ecology of motherhood: the structuring of lactation costs by chacma baboons. J. Anim. Ecol. 75, 875-886. (doi:10.1111/i.13652656.2006.01105.x

111. Garber PA, Bicca-Marques JC, de O Azevedo-Lopes MA. 2009 South American Primates, Developments in Primatology: Progress and Prospects (R.H. Tuttle, Ed). Springer Science + Business Media, University of Chicago, Illinois.

112. Trapanese C, Meunier H, Masi S. 2018 What, where and when: spatial foraging decisions in primates. Biol. Rev. 94, 483-502. (doi:10.1111/brv.12462)

113. Boesch C, Boesch H. 1989 Hunting behavior of wild chimpanzees in the Taï National Park. Am. J. Phys. Anthropol. 78, 547-73.

114. Gilby IC. 2006 Meat sharing among the Gombe chimpanzees: harassment and reciprocal exchange. Anim. Behav. 71, 953963. (doi: 10.1016/j.anbehav.2005.09.009)

115. Gilby IC, Emery Thompson M, Ruane J, Wrangham RW. 2010 No evidence of shortterm exchange of meat for sex among chimpanzees. J. Hum. Evol. 59, 44-53. (doi:10.1016/j.jhevol.2010.02.006)

116. Stanford CB, Wallis J, Mpongo E, Goodall J. 1994 Hunting decisions in wild chimpanzees. Behaviour 131, 1-18.

117. Tennie C, O'Malley RC, Gilby IC. 2014 Why do chimpanzees hunt? Considering the benefits and costs of acquiring and consuming vertebrate versus invertebrate prey. J. Hum. Evol. 71 38-45. (doi:10.1016/j.jhevol.2014.02.015)

118. Boesch C. 1994 Cooperative hunting in wild chimpanzees. Anim. Behav. 48, 653-667. (doi: 10.1006/anbe.1994.1285)

119. Mitani JC, Watts DP. 2001 Why do chimpanzees hunt and share meat? Anim. Behav. 61, 915-924. (doi:10.1006/anbe.2000.1681)

120. Gilby IC, Eberly LE, Wrangham RW. 2008 Economic profitability of social predation among wild chimpanzees: individual variation promotes cooperation. Anim. Behav. 75, 351-360. (doi: 
121. Williamson CS, Foster RK, Stanner SA, Buttriss JL. 2005 Red meat in the diet. Nutrition Bulletin 30, 323-355. (doi:10.1111/j.1467-3010.2005.00525.x)

122. Gilby IC, Wrangham RW. 2007 Risk-prone hunting by chimpanzees (Pan troglodytes schweinfurthii) increases during periods of high diet quality. Behav. Ecol. Sociobiol. 61, 1771-1779.

123. Wrangham RW, Conklin-Brittain N. 2003 Cooking as a biological trait. Comp. Biochem. Physiol. A 136, 35-46. (doi:10.1016/S10956433(03)00020-5)

124. Altmann SA. 2009 Fallback Foods, Eclectic Omnivores, and the Packaging Problem. Am. J. Phys. Anthropol. 140, 615629. (doi: 10.1002/ajpa.21097)

125. Samuni L, Preis A, Deschner T, Crockford C et al. 2018 Reward of labor coordination and hunting success in wild chimpanzees. Commun. Biol. 1, 138. (doi:10.1038/s42003018-0142-3)

126. Strum SC. 1975 Primate predation: interim report on the development of a tradition in a troop of olive baboons. Science 187, 755-7.

127. Fruth B, Hohmann G. 2018. Food sharing across borders: first observation of intercommunity meat sharing by bonobos at LuiKotale, DRC. Human Nature 29, 91-103. (doi: 10.1007/s12110-018-9311-9)

128. Gilby IC, Machanda ZP, O'Malley RC, Murray CM et al. 2017 Predation by female chimpanzees: Toward an understanding of sex differences in meat acquisition in the last common ancestor of Pan and Homo. J. Hum.

Evol. 110, 82-94. (doi: 10.1016/j.jhevol.2017.06.015)

129. Hobaiter C, Samuni L, Mullins C, Akankwasa WJ et al. 2017 Variation in hunting behaviour in neighbouring chimpanzee communities in the Budongo forest, Uganda.

PLoS ONE 12, e0178065. (doi:10.1371/journal.pone.0178065)

130. Altmann J, Samuels A. 1992 Costs of maternal care: infant-carrying in baboons. Behav. Ecol. Sociobiol. 29, 391-398. (doi:10.1007/BF00170168)

131. Marlowe FW. 2007 Hunting and gathering: the human sexual division of foraging labor. Cross-Cultural Res. 41, 170195.

132. Gilby IC, Connor RC. 2010 The role of intelligence in group hunting: Are chimpanzees different from other social predators? In "The Mind of the Chimpanzee: Ecological and Experimental Perspectives" (E.V. Lonsdorf, S.R. Ross, T. Matsuzawa, Eds), pp 220-233. University of Chicago Press, Chicago, IL.

133. Gilby IC, Machanda ZP, Mjungu DC, Rosen J et al. 2015 "Impact hunters" catalyse cooperative hunting in two wild chimpanzee communities. Phil. Trans. R. Soc. B 370, 20150005. (doi:10.1098/rstb.2015.0005)

134. Gavrilets S. 2015 Collective action problem in heterogeneous groups. Phil. Trans. R. Soc. B 370, 20150016. (doi:10.1098/rstb.2015.0016)

135. Meunier H. 2017 Do monkeys have a theory of mind? How to answer the question? Neurosci. Biobehav Rev. 82, 110-123. (doi: 10.1016/j.neubiorev.2016.11.007)

136. Mitani JC, Watts DP. 1999 Demographic influences on the hunting behavior of chimpanzees. Am. J. Phys. Anthropol. 109, 439-454.

137. Chang SWC, Brent $\amalg$, Adams GK, Klein JT et al. 2013 Neuroethology of primate social behavior. Proc. Natl Acad. Sci. 110, 1038710394. (doi: 10.1073/pnas.1301213110)

138. Samuni L, Preis A, Mielke A, Deschner T et al. 2018 Social bonds facilitate cooperative resource sharing in wild chimpanzees. Proc. Biol. Sci. 285, 20181643.

(doi:10.1098/rspb.2018.1643)

139. Procyk E, Wilson CR, Stoll FM, Faraut MC et al. 2016 Midcingulate Motor Map and Feedback Detection: Converging Data from Humans and Monkeys. Cereb. Cortex 26, 467-476. (doi: 10.1093/cercor/bhu213)

140. Mansouri FA, Koechlin E, Rosa MGP, Buckley MJ. 2017 Managing competing goals a key role for the frontopolar cortex. Nat. Rev. Neurosci. 18, 645-657. (doi: 10.1038/nrn.2017.111)

141. Louail M, Gilissen E, Prat S, Garcia C, Bouret S. 2019 Refining the ecological brain: Strong relation between the ventromedial prefrontal cortex and feeding ecology in five primate species. Cortex 118, 262-274. (doi:10.1016/j.cortex.2019.03.019)

142. Aiello LC, Wheeler P. 1995 The Expensive-Tissue Hypothesis: The Brain and the Digestive System in Human and Primate Evolution. Curr. Anthropol. 36, 119-221. (doi $: \underline{10.1086 / 204350}$ )

143. Bramble DM, Lieberman DE. 2004 Endurance running and the evolution of
Homo. Nature 432, 345-352. (doi:10.1038/nature03052)

144. Ungar PS. 2007 Evolution of the human diet, The Known, the Unknown, and the Unknowable. Oxford University Press, Oxford.

145. Zink ZD, Lieberman DE, Lucas PW. 2014 Food material properties and early hominin processing techniques. J. Hum. Evol. 77, 155166. (doi: 10.1016/j.jhevol.2014.06.012)

146. Harmand S, Lewis J, Feibel C, Lepre CJ et al. 2015 3.3-million-year-old stone tools from Lomekwi 3, West Turkana, Kenya. Nature 521, 310-315. (doi:10.1038/nature14464)

147. McPherron S, Alemseged Z, Marean CG, Reed D et al. 2010 Evidence for stone-toolassisted consumption of animal tissues before 3.39 million years ago at Dikika, Ethiopia. Nature 466, 857-860. (doi:10.1038/nature09248)

148. Smith AR, Carmody RN, Dutton RJ, Wrangham RW. 2015 The significance of cooking for early hominin scavenging. J. Hum. Evol. 84, 62-70.

(doi:10.1016/j.jhevol.2015.03.013)

149. Wrangham RW, Jones JH, Laden G, Pilbeam D et al. 1999 The Raw and the Stolen: Cooking and the Ecology of Human Origins. Curr. Anthropol. 40, 567-594. (doi:10.1086/300083)

150. Roebroeks W, Villa P. 2011 On the earliest evidence for habitual use of fire in Europe. Proc. Natl. Acad. Sci. USA 108, 52095214. (doi : 10.1073/pnas.1018116108)

151. Carmody RN, Dannemann M, Briggs AW, Nickel B et al. 2016. Genetic Evidence of Human Adaptation to a Cooked Diet. Genome Biol. Evol. 8, 1091-1103. (doi : 10.1093/gbe/evw059)

152. Bax M-L, Buffière C, Hafnaoui N, Gaudichon C et al. 2013 Effects of Meat Cooking, and of Ingested Amount, on Protein Digestion Speed and Entry of Residual Proteins into the Colon: A Study in Minipigs. PLoS ONE 8(4), e61252.

(doi:10.1371/journal.pone.0061252)

153. Carmody RN, Weintraub GS, Wrangham RW 2011. Energetic consequences of thermal and nonthermal food processing. Proc. Natl. Acad. Sci. USA 108, 19199-19203. (doi: 10.1073/pnas.1112128108)

154. Simmen B, Pasquet $P$, Masi $S$, Koppert GJA, et al. 2017 Primate energy input and the evolutionary transition to energy-dense diets in humans. Proc. R. Soc. B 284, 20170577. (doi :10.1098/rspb.2017.0577) 
155. Wobber V, Hare B, Wrangham R. 2008 Great apes prefer cooked food. J. Hum. Evol. 55, 340-348.

156. Warneken F, Rosati AG. 2015 Cognitive capacities for cooking in chimpanzees. Proc. R. Soc. B. 282, 20150229

157. Yu Y, Morton JD, Clerens S, Dyer JM. 2017 Cooking-Induced Protein Modifications in Meat. Compr. Rev. Food. Sci. Food Saf. 16, 141-159 (doi:10.1111/1541-4337.12243)

158. Goren-Inbar N, Alperson N, Kislev ME, Simchoni O et al. 2004. Evidence of Hominin Control of Fire at Gesher Benot Ya'aqov, Israel. Science 304, 725-727. (doi: 10.1126/science.1095443)

159. Carrier DR, Kapoor A, Kimura T, Nickels MK et al. 1984 The energetic paradox of human running and hominid evolution. Curr. Anthropol. 25, 483-495. (doi: 10.1086/203165)
160. Liebenberg L. 2006 Persistence hunting by modern hunter-gatherers. Curr. Anthropol. 47, 1017-1026. (doi: 10.1086/508695)

161. Lieberman DE. 2015 Human locomotion and heat loss: an evolutionary perspective. Compr. Physiol. 5, 99-117. (doi: 10.1002/cphy.c140011)

162. Steudel-Numbers KL, Wall-Scheffler CM. 2009 Optimal running speed and the evolution of hominin hunting strategies. J. Hum. Evol. 56, 355-360.

(doi: 10.1016/j.jhevol.2008.11.002)

163. Conard NJ, Serangeli J, Bigga G, Rots V. 2020 A 300,000-year-old throwing stick from Schöningen, northern Germany, documents the evolution of human hunting. Nat. Ecol. Evol. 4, 690-693. (doi: 10.1038/s41559-0201139-0)

164. Kuhn SL, Stiner MC. 2006 What's a mother to do? The division of labor among Neandertals and modern humans in Eurasia [and Comments and Reply]. Curr. Anthropol. 47, 953-980. (doi:10.1086/507197)

165. Hawkes K, O'Connell JF, Blurton Jones NG. 2001 Hadza meat sharing. Evol. Hum. Behav. 22, 113-142 (doi: 10.1016/S10905138(00)00066-0)

166. Kaplan H, Hill K. 1985 Hunting ability and reproductive success among male Ache foragers: preliminary results. Curr. Anthrop. 26, 131-133. (doi :10.1086/203235)

167. Nakamura M, Hosaka K, Itho N, Matsumoto T. 2019. Wild chimpanzees deprived a leopard of its kill: Implications for the origin of hominin confrontational scavenging. J. Hum. Evol. 131, 129-138. (doi:10.1016/j.jhevol.2019.03.011) 